\title{
Redeployment of Dental Core Trainees in the United Kingdom due to Coronavirus Disease 2019
}

\author{
Misha Patel ${ }^{1} \quad$ Payvand Menhadji $^{1} \quad$ Serena Mayor ${ }^{1}$ \\ ${ }^{1}$ Oral Surgery Department, Floor 23, Guys Hospital, Oral Surgery, \\ Great Maze Pond, London, United Kingdom
}

Eur J Dent:2020;14(suppl S1):S44-S49

\begin{abstract}
Address for correspondence Misha Patel, BDS (Hons), Oral Surgery Department, Floor 23, Guys Hospital, Great Maze Pond, London, SE1 9RT, United Kingdom (e-mail: misha_patel3@hotmail.co.uk).
\end{abstract}

\begin{abstract}
Keywords

- COVID-19

- dental education

- personal protective equipment

- redeployment

Objective The coronavirus disease 2019 (COVID-19) pandemic has affected professionals in all fields; none more so than medical and dental professionals. As dental core trainees (DCT) working in hospitals, we have been at the forefront of the crisis and one of the first in line for redeployment. Therefore, we decided to investigate the impact of COVID-19 on the redeployment of DCTs across the UK.

Materials and Methods Data for this study was collected and shared between three project researchers. All researchers were undergoing dental core training in Oral Surgery and Restorative dentistry at Guy's Hospital, London. An online survey was sent out via email and online social media platforms to reach as many DCTs as possible in the United Kingdom. Implied consent was obtained by respondents on submission of the survey.

The survey consisted of five sections and was branched, with respondents answering different sections depending on their redeployment status. No qualitative data was collected, as all questions included in the survey were dichotomous or multiple-choice questions. The last two questions were in the form of a 5-point Likert scale, inviting respondents to rate five statements from strongly agree to strongly disagree.

Results A total of 150 participants responded, of which $34 \%$ had been redeployed due to the pandemic. The majority of DCTs were redeployed to an intensive care unit or similar setting, and over $75 \%$ of those redeployed were working with either COVID-19 positive/suspect patients. Additionally, $23.8 \%$ of respondents had stopped patient contact due to their medical status.

Conclusion Many DCTs have been deployed to departments outside of their specialty and expressed some anxiety as a result. Inevitably, this has resulted in disruption to their training program and education over the last few months. The response across the United Kingdom has been understandably variable due to the differing demands of the hospital trusts within which the DCTs work.
\end{abstract}

\section{Introduction}

Coronavirus disease 2019 (COVID-19) has posed significant challenges for dentistry with all levels of dental training affected in countries around the world. ${ }^{1}$ The arrival of
COVID-19 was unexpected, and indeed the speed of reaction and type of response to this disease will vary across the globe due to differing health care systems, economies, and political ideologies.
DOI https://doi.org/ $10.1055 / \mathrm{s}-0040-1719216$ ISSN $1305-7456$.
(C) 2020. European Journal of Dentistry.

This is an open access article published by Thieme under the terms of the Creative Commons Attribution-NonDerivative-NonCommercial-License, permitting copying and reproduction so long as the original work is given appropriate credit. Contents may not be used for commercial purposes, or adapted, remixed, transformed or built upon. (https://creativecommons.org/licenses/by-nc-nd/4.0/)

Thieme Medical and Scientific Publishers Pvt. Ltd., A-12, 2nd Floor, Sector 2, Noida-201301 UP, India 
In the United Kingdom, there are over 600 dental core trainees (DCTs) in training at one time. Dental core training is available at three levels: DCT level 1 (DCT1), level 2 (DCT2), and level 3 (DCT3). ${ }^{2}$ The program is designed to enhance clinical leadership and management competencies to promote high ethical standards leading to quality patient care. While most programs are hosted in secondary care trusts, some posts are available in primary care and specialist dental services.

The week of the 26th March 2020 saw general dental practitioners ordered to put down their drills and close all practices; DCTs on the other hand were asked to step up and undertake new roles out of the realms of familiarity. They were redeployed to areas in need, such as emergency departments (EDs), hospital wards, intensive care units (ICUs), and virtual hubs. It was reported that over 13,000 dental professionals had signed up to volunteer for redeployment in the United Kingdom, highlighting the profession's willingness to unite with the rest of the National Health Service (NHS) workforce to win the fight against COVID-19. ${ }^{3}$

The DCTs possess valuable skills placing them in good stead to contribute to the COVID-19 response. Such skills include history taking, triaging, prescribing, cannulation, and suturing. DCTs can additionally provide reassurance and support to worried families and patients. Although many DCTs have completed multiple years of dental training, it is prudent to assume that they would never have envisaged their role in contributing to a pandemic-a medical emergency on a global scale. Working outside of one's comfort zone during the COVID-19 pandemic may understandably provoke anxiety, and this is an aspect of the pandemic which we aimed to explore through our research.

\section{Materials and Methods}

\section{Objectives}

The primary aim of this research project was to investigate how DCTS around the United Kingdom have been asked to respond to the pandemic. We explored whether the DCTs were redeployed and which departments they were sent to. We investigated the impact of their medical histories on their job roles, the availability of personal protective equipment (PPE) and the DCTs' feelings toward redeployment. Finally, we aimed to assess the repercussions of the pandemic on the DCTs learning and training program.

\section{Data Collection}

An online survey was piloted by colleagues at Guy's Hospital before being distributed across the United Kingdom, via email and various social media platforms over a 2-week period, from April 27 to May 11, 2020. Participation was anonymous and voluntary; implied consent was obtained by respondents on completion of the survey and there was no incentive to participate.

\section{Survey Design}

The survey consisted of five sections, with respondents answering different sections depending on whether they had discontinued work, continued working in the same department(s), or if they had been redeployed. In total, the survey consisted of 21 questions; however, the survey was branched, whereby the questions were variable depending on the participants' responses.

No qualitative data was collected; all questions included in the survey were dichotomous or multiple choice. The last two questions in the survey invited respondents to rate five statements from strongly agree to strongly disagree, using a 5-point Likert scale. This allowed respondents to rank how confident and anxious they felt about being redeployed.

Demographic variables in the survey included age group, training level, specialty, and hospital deanery. These questions ensured that anonymity was maintained, and respondents were not asked to reveal any identifiable information.

\section{Results}

From a total approximate of 677 DCTs in the United Kingdom, 150 responses were obtained, equaling a response rate of $22 \%$. All questionnaires were completed satisfactorily and included within the study.

The average age range was 20 to 25 years, and the modal training level was DCT1. Results found that $60.7 \%$ of respondents were from oral and maxillofacial surgery (OMFS). Respondents represented deaneries in all regions of the United Kingdom; however, the majority representative area was London and Kent, Surrey, Sussex, at 29.3\%. See -Figs. 1 and 2 for full demographics of specialty and region.

In terms of medical histories, $14 \%$ of respondents had medical conditions, with $23.8 \%$ of those ceasing patient contact due to being within a high-risk category for COVID-19.

Only $46 \%$ of respondents remained working within their own department(s) of which $11 \%$ felt that they did not have sufficient or correct PPE as per current national guidelines, that is, Public Health England. Overall, 59.3\% had their job roles changed and in $72 \%$ there was a change in shift pattern.

\section{Redeployment}

-Fig. 3 provides a summary as to the redeployment statuses of the DCTs who responded to the survey and - Table 1 details the departments to which participants had been

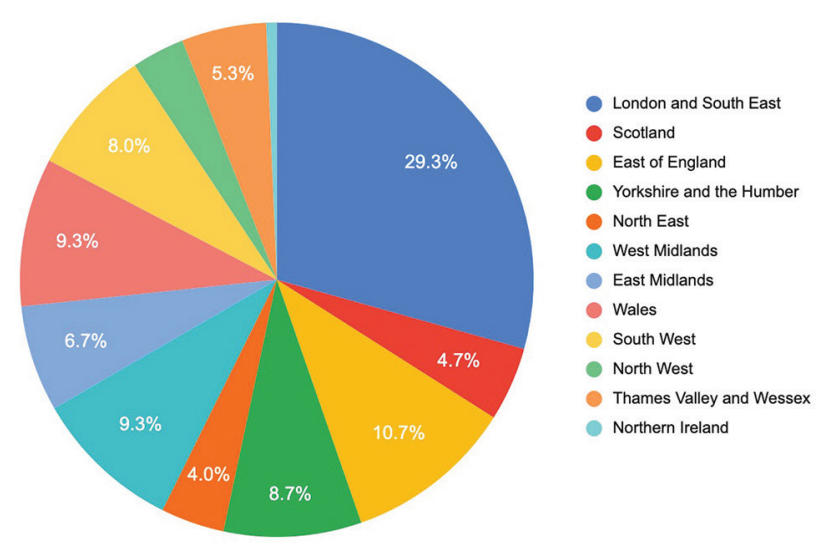

Fig. 1 Demographics of deaneries of the respondents. 


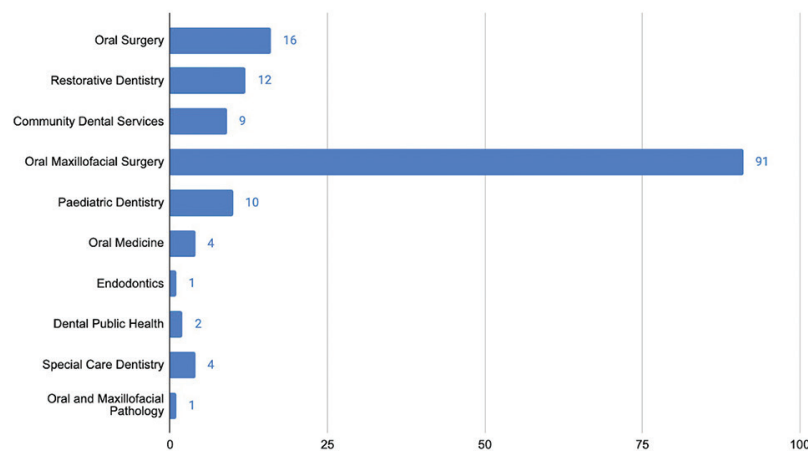

Fig. 2 Primary departments of the respondents.

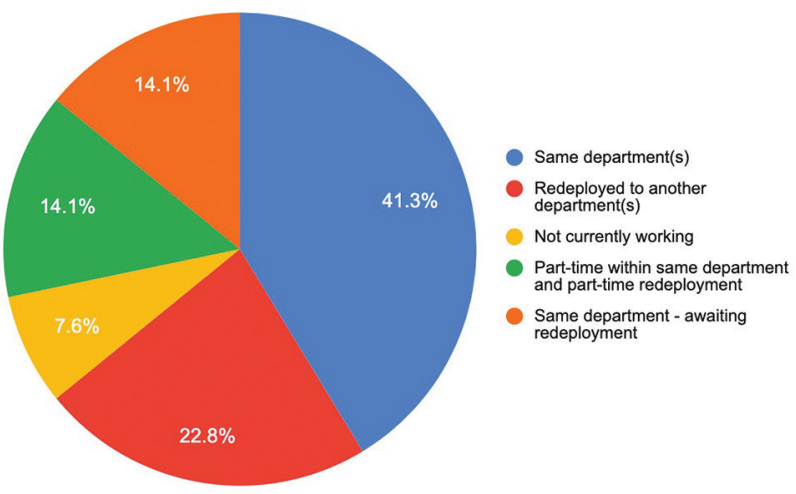

Fig. 3 Graph showing where dental core trainees are currently working.

redeployed. Several DCTs went on to specify that alongside

Table 1 Table depicting departments to which dental core trainees have been redeployed

\begin{tabular}{|l|l|}
\hline Department & $\begin{array}{l}\text { Numbers } \\
\text { redeployed }\end{array}$ \\
\hline ITU/critical care & 16 \\
\hline Renal wards & 12 \\
\hline COVID-19 testing & 4 \\
\hline Accident and emergency & 3 \\
\hline COVID-19 ward & 2 \\
\hline Maternity & 2 \\
\hline Neurosurgery/ENT/ophthalmology & 2 \\
\hline Respiratory (ITU step-down) & 2 \\
\hline Emergency dental service & 2 \\
\hline Community district nursing & 2 \\
\hline High dependency unit & 1 \\
\hline Surgical and trauma orthopedic wards & 1 \\
\hline ENT & 1 \\
\hline Obstetrics & 1 \\
\hline Acute medicine & 1 \\
\hline Occupational health & 1 \\
\hline Oral maxillofacial surgery & 1 \\
\hline
\end{tabular}

Abbreviations: COVID-19, coronavirus disease 2019; ENT, ear, nose, and throat; ITU, intensive therapy unit. the departments listed in the table, they also contributed to triaging patients, performing video consultations, and working on the adult emergency dental clinics. We found that the majority (28\%) of DCTs have been redeployed to ICU or other similar settings.

-Fig. 4 depicts the variation in shift patterns undertaken by those redeployed, there were some notable changes from their normal scheduling. Of those redeployed, $24.6 \%$ started working weekends and $38.6 \%$ began an earlier shift pattern. In total, $28.1 \%$ of respondents worked longer days with days off with $45.6 \%$ of DCTs working their normal hours.

Results showed that $42.1 \%$ of participants felt that they did not receive clear guidance on what their new job role would entail; however, $71.9 \%$ did receive additional training. Over $75 \%$ of DCTs were redeployed to areas treating COVID-19 positive or COVID-19 suspect patients, yet $14 \%$ reported that they did not have appropriate PPE in accordance with national guidelines.

Feelings and attitudes toward redeployment were varied. From the DCTs who responded, $52.6 \%$ felt some degree of anxiety whereas when asked how confident they felt about redeployment $43.9 \%$ of individuals expressed confidence. These results are displayed in - Fig. 5 that illustrates participants expressing greater levels of anxiety compared with confidence.

\section{Discussion}

\section{Personal Protective Equipment}

Appropriate PPE is essential for the safe performance of dentistry during the COVID-19 outbreak. Nationwide efforts are underway to resolve shortages of PPE and deliver equipment

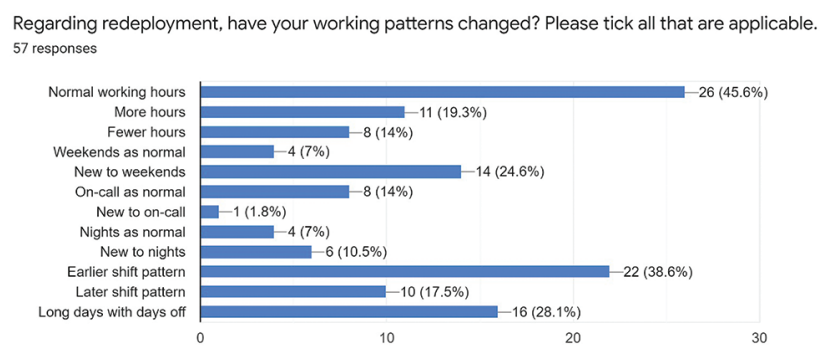

Fig. 4 Graph showing alterations in working pattern.

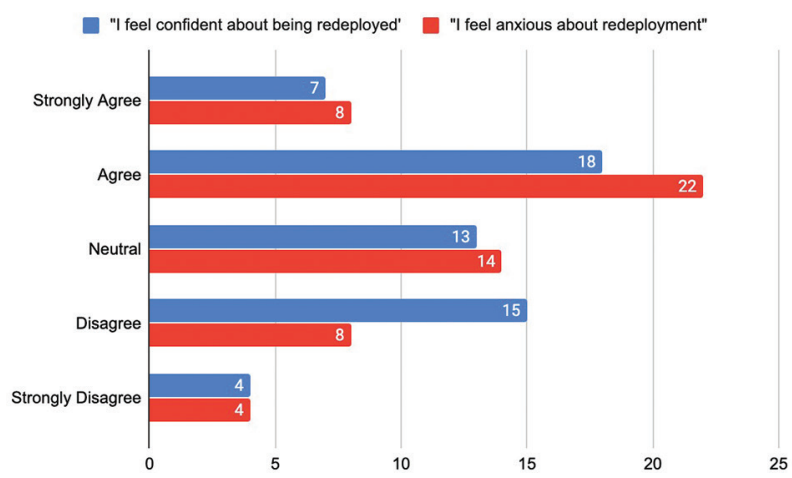

Fig. 5 Chart to demonstrate feelings toward redeployment. 
to where it is most needed. Our results found that $14 \%$ of those working in their own department(s) felt that they did not have sufficient or correct PPE as per current national guidelines. There has been conflicting guidance regarding essential PPE from various professional bodies at the start of the pandemic. These differing opinions may have been the cause of anxiety and confusion felt amongst trainees. Peng et al explain how dental professionals are exposed to a greater risk of $\beta$-coronavirus (2019-nCoV) infection due to the exposure to saliva, blood, and other body fluids and the face-to-face communication with patients. ${ }^{4}$ Therefore, it is important that all dental professionals have the correct PPE. This is reiterated by Ather et al who explain and demonstrate the appropriate use of PPE and hand hygiene practices. ${ }^{5}$

\section{Volunteering and Redeployment}

The General Dental Council supports the redeployment of dentists, appreciating that they will be undertaking roles beyond their usual scope of practice. ${ }^{6}$ However, they did state that dentists must be trained, competent, and indemnified for those tasks. Under the Coronavirus Act 2020, the NHS provides indemnity for work undertaken while redeployed. ${ }^{7}$

- Table 1 depicts the 17 departments to which DCTs have been redeployed, reflecting the versatility and adaptability of dental professionals. ${ }^{8}$ The ability to utilize and apply the skills and knowledge developed during dental school and the few years beyond to contribute to medical wards including maternity and intensive therapy unit (ITU), of which they would previously had very limited experience, is commendable. This is particularly admirable when $28.1 \%$ of respondents received no further training for their new roles. It is interesting to note that the majority of those redeployed to ICU were undertaking DCT in OMFS. This may be due to the fact that they would have been exposed to these units early on in their training, prior to the COVID-19 outbreak unlike those DCTs working in other specialties. ${ }^{9}$

Although not the original posts for which these trainees would have applied, approaching such challenges in their career should be looked upon positively, allowing these young dentists to enhance their learning and develop transferable. As advised by Health Education England in a letter addressed to all trainees, DCTs have been advised to continue learning, albeit not in the manner originally planned..$^{10}$ Embracing and engaging in these newly appointed roles may prove invaluable, improving their knowledge in other medical fields, and contributing to character building. As reported previously by OMFS DCTs, working under pressure has taught them resilience and vastly improved their medical knowledge; similarly deployment to units such as accident and emergency and ITU can only enhance these feelings and skills. ${ }^{9}$ This situation truly allows for these DCTs to appreciate early on in their career that commitment to patient care extends far beyond the oral cavity. This is supported by Professor Paul Coulthard, the president of the British Association of Oral Surgeons, who expressed his admiration of the dedication displayed by the dental profession during the pandemic, including DCTs. ${ }^{11}$

\section{Attitudes and Feelings toward Redeployment}

Feelings toward redeployment were variable, $52.6 \%$ of DCTs felt some degree of anxiety about redeployment. Understandably, a new position may cause anxiety as there is limited guidance and support compared with normal circumstances.

Of those individuals who responded, $43.9 \%$ of individuals were confident to be redeployed; this confidence may be a result of continued training in a hospital environment and these DCTs felt that they could be better utilized elsewhere during these unprecedented times. This positive behavior was beneficial in the nationwide redeployment process and demonstrated a significant proportion of DCTs felt comfortable taking on new roles. However, it should not be overlooked that $52.6 \%$ of DCTs who were redeployed to other departments, did not feel confident working elsewhere. Hence, it may have been more appropriate for DCTs to have been given a choice on redeployment or asked where they may feel comfortable to work.

Of those redeployed, $40.4 \%$ stated that they did not have a choice on which department to be redeployed to, which may have increased anxiety levels. Of those respondents who had been redeployed, $75.4 \%$ were treating COVID-19 positive or COVID-19 suspected patients which may have been a contributory factor. Another possible factor leading to decreased confidence levels is lack of appropriate PPE. Of those who had been redeployed, $14 \%$ claimed not to have PPE as per current national guidelines. There should not have been any respondents who were working without the correct PPE; however, it has been recognized that local guidelines within the country did not always correspond to national guidelines. In addition, dentists were categorized as one of the most high-risk groups for transmission of $\beta$-coronavirus (2019-nCoV), which could have also led to increased anxiety within this cohort. ${ }^{12}$

This corresponds to similar research by Ahmed et al, who concluded that dental practitioners around the world are fearful and anxious working during the COVID-19 pandemic, despite having a high standard of knowledge and practice. ${ }^{13}$ Additionally, Professor Paul Coulthard expressed his own anxiety to provide clinical care without the appropriate PPE. He explained that this is an issue due to the increased demands for PPE worldwide. ${ }^{14}$

\section{Dental Core Trainees Training}

All respondents were either working in a different department or undergoing modified job roles within their department. This will undoubtedly have impacted upon their training and education. Guidance from British Dental Association states that trainees should use this time to engage in their experiences and record them on their electronic portfolios..$^{15}$ They recognize that there will be "loss of core clinical training time" but suggest that DCTs will develop their leadership and management skills during the pandemic. The BDA suggests that nonclinical time may be compensated for if and when the ongoing situation resolves. 
However with 3 months left of the training year, this seems unlikely. Many DCTs rely on this training to support their career choices and going forward it will be unclear if this has affected ongoing training.

Applications for the next stage of core training were due in February 2020, prior to the plight of COVID-19 in the United Kingdom. Therefore, it could be speculated that had the existing DCTs anticipated the effects of the pandemic on their current training posts, that is, reduced training or incomplete rotations, there may have been more applicants for an additional year of training.

\section{Limitations}

Our response rate of $22 \%$ was critically low. We believe this is due to the fact that we were unable to distribute the survey to all DCTs, and this highlights difficulty in communication with the cohort. There is currently no available means to contact the entire cohort and as a result, we distributed the survey predominantly via social media platforms and email. We feel improved communication channels would help improve the training program and encourage more effective dissemination of information. Our reduced response rate may also be due to the fact that trainees were undertaking different job roles and may not be routinely checking their emails.

The proportion of responses from certain departments was higher than others, most notably OMFS DCTs. The reason behind this is due to the fact that there are considerably more OMFS DCTs compared with those in other specialties across the United Kingdom.

The timeframe for data collection may have impacted the trainees' feelings toward redeployment. It is likely that trainees became more accustomed to the idea of redeployment, having been advised by colleagues/their hospital trusts that redeployment was imminent; thus, our results may appear to depict higher confidence levels than in the initial stages of COVID-19.

\section{Conclusion}

To conclude, this study has shown that a significant number of DCTs had their job roles changed or were redeployed during their training year. This may have induced anxiety in the DCTs and is likely to have had an impacted upon their training. Although DCTs follow a national curriculum, we found that there have been significant differences in how DCTs have been asked to respond to the COVID-19 pandemic.

COVID-19 represents an accelerating challenge that will pose countless uncertainties for DCTs and other health care professionals. The way in which this situation is best managed will continue to evolve at every level. To meet the needs of patients during these unprecedented times, we must reconfigure how our training programs work to ensure effective cover for the mounting inpatient workload. Furthermore, the question poses how this outbreak may have affected these trainees' crucial training year and their future career plans. This will become more evident in the upcoming years, but undoubtedly DCTs have gained invaluable experience and skills during this pandemic.

It is heartening to see the DCTs stepping up in their job roles, contributing to the fight against COVID-19. The compassion, resilience, and courage displayed in these trying times is inspiring and proves the dental profession is one to which we are proud to belong.

\section{Conflict of Interest}

None declared.

\section{Acknowledgments}

The authors would like to thank Chris Sproat, Vinod Patel, George Paolinelis, and Jerry Kwok for their guidance throughout this study. They also thank all anonymous participants who took the time to respond to our survey.

\section{References}

1 Quinn B, Field J, Gorter R, et al. COVID-19: The immediate response of european academic dental institutions and future implications for dental education. Eur J Dent Educ 2020; 24(4):811-814 doi:10.1111/eje.12542

2 COPDEND. (2016) UK dental core training curriculum. Available at: https://www.copdend.org/wp-content/uploads/2018/09/2 016-12-14-UK-DCT-CurriculumDecember-2016.pdf. Accessed June 14,2020

3 Thomson A, Chohan P, Ismail MJ, Khalid S, Patel N, Uppal S. Out of our comfort zone. Br Dent J 2020;228(8):568

4 Peng X, Xu X, Li Y, Cheng L, Zhou X, Ren B. Transmission routes of 2019-nCoV and controls in dental practice. Int J Oral Sci 2020;12(1):9

5 Ather A, Patel B, Ruparel NB, Diogenes A, Hargreaves KM. Coronavirus disease 19 (COVID-19): implications for clinical dental care. J Endod 2020;46(5):584-595

6 General Dental Council. Responding to COVID-19: providing treatment in an uncertain time. 2020. Available at: https:// www.gdc-uk.org/news-blogs/blog/detail/blogs/2020/03/26/ responding-to-covid-19-providing-treatment-in-uncertaintimes. Accessed May 2020

7 Coronavirus Act. 2020. 2020. UK public general acts. c7 s 11. Available at: https://www.legislation.gov.uk/ukpga/2020/7/ section/11/enacted. Accessed May 2020

8 NHS England. Redeploying the clinical dental workforce to support the NHS clinical delivery plan for COVID-19. 2020. Available at: https://www.england.nhs. uk/coronavirus/wp-content/uploads/site s/52/2020/04/ C0301-Permissions-Redeploying-our-people-clinicaldental-workforce-v2.pdf. Accessed May 2020

9 Fernando S. 2020. Redeployment to the intensive care unit. COVID-19: views from the NHS frontline. RCS (Eng). Available at: https://www.rcseng.ac.uk/news-and-events/blog/redeployment-to-the-intensive-care-unit/. Accessed June 2020

10 Health Education England. Supporting the COVID-19 response: guidance regarding medical education and training. Available at: https://www.hee.nhs.uk/coronavirus-information-trainees. Accessed May 2020

11 Coulthard P. Dentistry and coronavirus (COVID-19) - moral decision-making. Br Dent J 2020;228(7):503-505 
12 The New York Times. (New York). The workers who face the greatest coronavirus risk. 2020. Available at https:// www.nytimes.com/interactive/2020/03/15/business/economy/coronavirus-worker-risk.html? searchResultPosition=3. Accessed May 2020

13 Ahmed MA, Jouhar R, Ahmed N, et al. Fear and practice modifications among dentists to combat novel coronavirus disease (COVID-19) outbreak. Int J Environ Res Public Health 2020;17(8):2821
14 Coulthard P. The oral surgery response to coronavirus disease (COVID-19). Keep calm and carry on?. Oral Surg 2020; 13(2):95-97 doi:10.1111/ors.12489

15 FAQ for dental core trainees during the current COVID-19 situation. Available at: https://bda.org/advice/Coronavirus/ Documents/faqs_dental_core_trainees_covid-19.pdf. Accessed March 30, 2020 